OPEN ACCESS

Edited by:

Mathias Baumert,

University of Adelaide, Australia

Reviewed by:

Herbert Jelinek,

Charles Sturt University, Australia

Rezzak Yilmaz,

University of Tuebingen, Germany

${ }^{*}$ Correspondence:

Huazheng Liang a.liang@neura.edu.au;

Shaoshi Wang

wangshaoshi@126.com

Specialty section: This article was submitted to Autonomic Neuroscience, a section of the journal

Frontiers in Neurology

Received: 23 October 2016 Accepted: 15 March 2017

Published: 03 April 2017

Citation:

Huang H, Zheng T, Liu F, Wu Z,

Liang H and Wang S (2017)

Orthostatic Hypotension Predicts

Cognitive Impairment in the Elderly:

Findings from a Cohort Study.

Front. Neurol. 8:121.

doi: 10.3389/fneur.2017.00121

\section{Orthostatic Hypotension Predicts Cognitive Impairment in the Elderly: Findings from a Cohort Study}

\author{
Haixia Huang ${ }^{1}$, Tianheng Zheng ${ }^{1}$, Fang Liu ${ }^{2}$, Zhuoli Wu ${ }^{1}$, Huazheng Liang ${ }^{3 *}$ and \\ Shaoshi Wang ${ }^{1 *}$ \\ 'Department of Neurology, North Sichuan Branch of Shanghai No.1 People's Hospital, Shanghai, China, ${ }^{2}$ Department of \\ Neurology, The Affiliated Hospital of Guizhou Medical University, Guiyang, China, ${ }^{3}$ Neuroscience Research Australia, \\ Randwick, NSW, Australia
}

Background: Orthostatic hypotension $(\mathrm{OH})$ is a known risk factor for cerebral ischemia, but its correlation with cognitive impairment $(\mathrm{Cl})$ is not well established.

Objective: The aim of this study is to explore the relationship between $\mathrm{OH}$ and $\mathrm{Cl}$ in the elderly.

Methods: The study group consisted of $44 \mathrm{OH}$ patients who presented with drowsiness, vertigo, and fatigue between January 2009 and December 2011 (OH group). Eighty-eight healthy elderly were paired with those in the $\mathrm{OH}$ group in a 1:2 based on their education levels (NOH group). Baseline sociodemographic information and cognition-related measures were collected for both groups. Cognitive function was assessed 4 years later using MMSE.

Results: The overall incidence of $\mathrm{Cl}$ was $14.0 \%$ among the 114 subjects who completed the follow-up assessment. There was a significant difference in the incidence of $\mathrm{Cl}$ between the $\mathrm{OH}$ group (23.7\%) and the $\mathrm{NOH}$ group (9.2\%) $\left(\chi^{2}=4.399, P=0.036\right)$. After excluding the influence of age (OR $=1.199,95 \% \mathrm{Cl}: 1.072-1.340, P=0.001)$ and education years $(\mathrm{OR}=0.568,95 \% \mathrm{Cl}: 0.371-0.869, P=0.009), \mathrm{OH}(\mathrm{OR}=4.047,95 \%$ Cl: 1.144-14.313, $P=0.030$ ) became an independent risk factor for $\mathrm{Cl}$.

Conclusion: $\mathrm{OH}$ can lead to $\mathrm{Cl}$. We suggest that future studies, with a larger sample size, use $\mathrm{OH}$ exposure time instead of $\mathrm{OH}$ exposure population to verify the conclusion of this study.

Keywords: orthostatic hypotension, cognitive impairment, elderly, cohort study

\section{INTRODUCTION}

Aging with the development of cognitive impairment (CI) has attracted extensive attention due to the increasing aging population (1-3). Studies have shown that hypertension is an independent risk factor for developing $\mathrm{CI}$ in the elderly $(4,5)$. However, other studies showed that hypotension can also lead to $\mathrm{CI}$ in the elderly $(6,7)$. Orthostatic hypotension $(\mathrm{OH})$, a phenomenon of decreased blood pressure when changing from a supine position to the orthostatic position, is often accompanied by drowsiness, vertigo, blurred vision, and other signs of brain hypoperfusion. It is 
common in the elderly, with an incidence of 5-30\% (8). Colloby et al. proposed that decreased systolic blood pressure (SBP) in the orthostatic position might be one of the causes of deep white matter hyperintensity (9). A recent study also reported that $\mathrm{OH}$ was an independent risk factor for ischemic stroke (10), which increased the incidence of senile dementia (8). Because this study focused on the effect of $\mathrm{OH}$ with baseline hypotension on cognitive performance, it is not conclusive that isolated $\mathrm{OH}$ leads to CI. This 7-year prospective cohort study aimed to investigate the relationship between $\mathrm{OH}$ and $\mathrm{CI}$ in the elderly.

\section{SUBJECTS AND METHODS}

\section{Subjects}

Forty-four OH patients who visited our hospital between January 2009 and December 2011 due to drowsiness, vertigo, and fatigue were enrolled in the study group ( $\mathrm{OH}$ group). Eighty-eight healthy elderly were paired with those in the $\mathrm{OH}$ group in a 1:2 based on their education levels ( $\mathrm{NOH}$ group). The inclusion criteria were as follows: aged 60 years and older, secondary school or above education, fit the 1996 American Autonomic Society/American Academy of Neurology diagnostic criteria of $\mathrm{OH}$ [SBP dropped more than $20 \mathrm{mmHg}$ or diastolic blood pressure (DBP) more than $10 \mathrm{mmHg}$ when changed from the supine position to the orthostatic position], good understanding of questions or content of the questionnaire, no difficulty in communicating with researchers, and being conscious and able to give informed consent. Exclusion criteria were as follows: confirmed Alzheimer's disease using the diagnostic criteria for probable AD dementia from NINCDS-ADRDA (11); vascular dementia; dementia due to other causes; confirmed multiple system atrophy; Parkinson's disease; cerebral infarction; intracerebral hemorrhage; other cerebrovascular diseases; MMSE score less than 24; depression (using the Self-Rating Depression Scale); anxiety (using the Self-Rating Anxiety Scale); other psychiatric problems; traumatic injury to the head; visual and auditory deficits; hypertension; primary hypotension; postprandial hypotension; severe liver and kidney insufficiency; severe medical conditions such as pneumonia, coronary artery disease, and heart failure; cigarette and alcohol addiction; and abuse of medications. We have obtained ethical approval from the Human Research Ethics Committee of North Sichuan Branch, Shanghai No.1 People's Hospital.

\section{Methods}

\section{Baseline Information}

Baseline information was collected after obtaining the informed consent from the patients. It included sociodemographic information such as age, gender, education level, living alone or not, cognition-associated risk factors such as hypertension (5), smoking, presence of diabetes mellitus, supine SBP and DBP, head MRI, and Minimal Mental State Examination (MMSE). $\mathrm{OH}$ diagnosis was achieved by measuring supine blood pressure 2 min after lying in bed, followed by measuring the orthostatic blood pressure within 1-3 min after standing up quickly from the bed. BP was measured on the right arm, $3 \mathrm{~cm}$ above the cubital fossa, for 3 consecutive days at the same time each day. (The averages of results from the 3 consecutive days were compared.) The sphygmomanometer was kept in situ and on the same level as the patient's heart. MR imaging was performed using a GE $1.5 \mathrm{~T}$ superconducting MRI. Horizontal T1WI, T2WI, and FLAIR were collected regularly, and in some cases, coronal and sagittal T2WIs were collected. White matter lesions (WMLs) were assessed by specialists using the standard suggested by Fazekas et al. (12): 0 indicates no or a single punctate lesion, 1 indicates multiple punctate lesions, 2 indicates fusion or bridging of multiple lesions, and 3 indicates extensive fusion of WML.

\section{Follow-up Information}

Four years later, these patients were assessed with Minimal Mental State Examination (MMSE), and CI was diagnosed by neurologists using the MMSE scale during the interview. MMSE is widely used for cognitive assessment, which examines attention, orientation, memory, calculation, language, and visual spacing capabilities of cognitively impaired patients. It has a total score of 30 . If the score is between 24 and 27 , it is very likely that the patients have mild cognitive impairment (MCI), and if it is below 24, then the patient might have dementia. If the patient had a complaint of cognitive decline or the caregiver reported that the patient had cognitive decline in less than 4 years, the patient would be interviewed by an experienced neurologist, and MMSE was used to assess the patient's cognitive performance. If the score was lower than 24 , the patient was diagnosed with CI (13).

\section{Data Analysis}

Original data were checked and recorded in Epidata 3.0, followed by checking errors. SPSS 13.0 was used to analyze the data. Categorical data were represented as frequency or percentage and analyzed using Chi-square test. Non-parametric testing was used to analyze the difference in baseline information. Quantitative data were represented as average $\pm \mathrm{SD}$, and the difference in baseline information between groups was analyzed using $t$-test. Logistic regression model was established to predict the probability of developing CI, and it was tested bilaterally. The significant difference was indicated when $P$ was less than 0.05 .

\section{RESULTS}

\section{Baseline Data}

Of $44 \mathrm{OH}$ patients and 88 education-level paired normal patients, 68 were men and 64 were women. Their age ranged from 60 to 87 years with an average of $69.58 \pm 6.49$ years. The average education time was $11.70 \pm 2.04$ years. The average SBP and DBP on a supine position were $137.08 \pm 17.80$ and $85.03 \pm 11.48 \mathrm{mmHg}$, respectively. The percentage of patients living alone and smoking was 10.6 and $15.2 \%$, respectively. Twenty-four had diabetes (18.2\%). The percentage of WML $0,1,2$, and 3 was $45.5 \%$ (60), $34.1 \%$ (45), $15.2 \%(20)$, and $5.3 \%$ (7), respectively. There was no significant difference in baseline demographic information and cognition-related risk factors between the $\mathrm{OH}$ group and the normal controls $(P>0.05)$ (Table 1$)$. 
TABLE 1 | Comparison of baseline demographic information and cognition-related risk factors between the orthostatic hypotension (OH) and non-OH groups $(\bar{x} \pm \mathbf{s}$ or $n(\%))$.

\begin{tabular}{|c|c|c|c|c|c|}
\hline Variables & Total subjects (132) & OH group (44) & Non-OH group (88) & $t / \chi^{2} / Z$ & $P$ value \\
\hline Age & $69.58 \pm 6.49$ & $69.90 \pm 6.03$ & $68.92 \pm 7.34$ & 0.819 & 0.414 \\
\hline Male & $68(51.5)$ & $18(40.9)$ & $50(56.8)$ & 1.370 & 0.124 \\
\hline Education (years) & $11.70 \pm 2.04$ & $11.78 \pm 2.09$ & $11.52 \pm 1.95$ & 0.693 & 0.489 \\
\hline Living alone & $14(10.6)$ & $4(9.1)$ & $10(11.36)$ & 0.160 & 0.690 \\
\hline Smoking & $20(15.2)$ & $6(13.6)$ & $14(15.9)$ & 0.118 & 0.731 \\
\hline Diabetes & $24(18.2)$ & $10(22.7)$ & $14(15.9)$ & 0.917 & 0.338 \\
\hline Supine systolic blood pressure (SBP) & $137.08 \pm 17.80$ & $138.92 \pm 18.04$ & $135.86 \pm 17.78$ & 0.928 & 0.355 \\
\hline Orthostatic SBP & $115.45 \pm 17.41$ & $92.23 \pm 20.02$ & $125.38 \pm 17.01$ & 9.941 & $<0.001$ \\
\hline Supine diastolic blood pressure (DBP) & $85.03 \pm 11.48$ & $86.01 \pm 11.63$ & $83.67 \pm 11.19$ & 1.118 & 0.266 \\
\hline Orthostatic DBP & $72.82 \pm 11.75$ & $65.70 \pm 14.12$ & $80.16 \pm 10.08$ & 6.767 & $<0.001$ \\
\hline MMSE & $26.66 \pm 1.16$ & $26.41 \pm 1.26$ & $26.78 \pm 1.09$ & 1.768 & 0.079 \\
\hline White matter lesion category & & & & 1.580 & 0.115 \\
\hline 0 & $60(45.5)$ & $15(34.1)$ & $45(51.1)$ & & \\
\hline 1 & $45(34.1)$ & $19(43.2)$ & $26(29.5)$ & & \\
\hline 2 & $20(15.2)$ & $7(15.1)$ & $13(14.8)$ & & \\
\hline 3 & $7(5.3)$ & $3(6.8)$ & $4(4.5)$ & & \\
\hline
\end{tabular}

\section{Comparison of Baseline Information between Follow-up and Non-Follow-up Groups}

Among the 44 paired groups, 6 groups were not followed up for various reasons: 1 group had a death, 3 groups refused being followed up, and 2 groups lost contact. It was found that the education level of these 6 groups was lower than the other 38 groups $(t=4.016, P<0.001)$. There was no significant difference in other baseline information between them $(P>0.05)$ (Table 2).

\section{Comparison of MMSE between $\mathrm{OH}$ and Non-OH Groups}

Among the 114 subjects who completed the follow-up assessment, there was no significant difference in baseline MMSE score between the $\mathrm{OH}$ and non-OH groups. After 4 years, there was a significant difference between these two groups $(t=2.441$, $P=0.018)$. Within each group, the MMSE score also showed a significant decline (both $P<0.005$ ) (Table 3 ).

\section{Single-Factor Analysis for $\mathbf{C l}$}

Sixteen subjects were diagnosed with CI (incidence of 14.0\%) with 9 in the $\mathrm{OH}$ group (38 in total, incidence 23.7\%) and 7 in the non-OH group (total 76, incidence $9.2 \%$ ). There was a significant difference in the incidence of CI $\left(\chi^{2}=4.399, P=0.036\right)$. These subjects were further divided into two groups based on whether they developed CI. Variables such as age, gender, education years, living alone or not, smoking, diabetes, WML category, and $\mathrm{OH}$ were compared between groups. We found that there was a significant difference between the two groups in age $(t=2.958$, $P=0.004)$ and $\mathrm{OH}\left(\chi^{2}=4.399, P=0.036\right)$ (Table 4).

\section{Multifactor Analysis for $\mathbf{C l}$}

By taking CI as the dependent variable and age, education, and $\mathrm{OH}$ as independent variables, logistic regression analysis for multiple variables showed that $\mathrm{OH}(\mathrm{OR}=4.047,95 \% \mathrm{CI}: 1.144-$ $14.313, P=0.030)$ was an independent risk factor for CI after excluding the influence of age $(\mathrm{OR}=1.199,95 \% \mathrm{CI}: 1.072-1.340$,
TABLE 2 | Comparison of baseline demographic information and cognition-related risk factors between followed up group and nonfollowed up group $(\bar{x} \pm \mathbf{s}$ or $n(\%))$.

\begin{tabular}{|c|c|c|c|c|}
\hline Variables & $\begin{array}{l}\text { Non-followed up } \\
\text { group (6 groups) }\end{array}$ & $\begin{array}{l}\text { Followed up } \\
\text { group (38 } \\
\text { groups) }\end{array}$ & $t / \chi^{2} / Z$ & $P$ value \\
\hline Age & $71.53 \pm 5.68$ & $69.27 \pm 6.57$ & 1.382 & 0.169 \\
\hline Male & $8(44.4)$ & $60(52.6)$ & 0.417 & 0.518 \\
\hline Education (years) & $10.00 \pm 1.37$ & $11.96 \pm 2.00$ & 4.016 & $<0.001$ \\
\hline Living alone & $2(11.1)$ & $12(10.5)$ & 0.114 & 0.736 \\
\hline Smoking & $4(22.2)$ & $16(14.0)$ & 0.298 & 0.585 \\
\hline Diabetes & $5(27.8)$ & $19(16.7)$ & 0.651 & 0.420 \\
\hline $\begin{array}{l}\text { Supine systolic blood } \\
\text { pressure (SBP) }\end{array}$ & $139.23 \pm 19.45$ & $137.12 \pm 17.78$ & 0.462 & 0.645 \\
\hline Orthostatic SBP & $116.15 \pm 16.25$ & $114.32 \pm 16.02$ & 0.450 & 0.654 \\
\hline $\begin{array}{l}\text { Supine diastolic blood } \\
\text { pressure (DBP) }\end{array}$ & $84.13 \pm 10.32$ & $86.25 \pm 11.93$ & 0.713 & 0.478 \\
\hline Orthostatic DBP & $72.00 \pm 10.82$ & $72.88 \pm 11.97$ & 0.293 & 0.770 \\
\hline MMSE & $26.78 \pm 1.40$ & $26.64 \pm 1.12$ & 0.467 & 0.642 \\
\hline $\begin{array}{l}\text { White matter lesion } \\
\text { category }\end{array}$ & & & 0.521 & 0.615 \\
\hline 0 & 7 (38.9) & $53(46.5)$ & & \\
\hline 1 & 7 (38.9) & 38 (33.3) & & \\
\hline 2 & $3(16.7)$ & $17(14.9)$ & & \\
\hline 3 & $1(5.5)$ & $6(5.3)$ & & \\
\hline
\end{tabular}

$P=0.001)$ and education years $(\mathrm{OR}=0.568,95 \% \mathrm{CI}: 0.371-0.869$, $P=0.009$ ). Based on the predicted probability from the logistic regression model, an ROC curve was mapped. The area under the ROC curve was 0.816 (95\% CI: 0.710-0.922). The maximum point of Youden's index was considered as the cutoff point, and the prediction probability was 0.172 at this point. The sensitivity was $81.30 \%$, the specificity was $77.60 \%$, and the Youden's index was 0.589 (Table 5).

\section{DISCUSSION}

Studies have shown that hypotension is an independent risk factor for dementia, with brain hypoperfusion proposed to account for this $(14,15)$. But the relationship between $\mathrm{OH}$ and $\mathrm{CI}$ has 
TABLE 3 | Comparison of MMSE score between orthostatic hypotension $(\mathrm{OH})$ and non-OH groups.

\begin{tabular}{lcccc}
\hline Variables & OH group (38) & Non-OH group (76) & $\boldsymbol{t}$ & $\boldsymbol{P}$ value \\
\hline Baseline & $26.30 \pm 1.33$ & $26.48 \pm 1.22$ & 0.720 & 0.472 \\
Follow-up & $24.08 \pm 3.47$ & $25.58 \pm 2.16$ & 2.441 & 0.018 \\
$t$ & 3.683 & 3.163 & & \\
$P$ value & $<0.001$ & 0.002 & & \\
\hline
\end{tabular}

TABLE 4 | Single-factor analysis for cognitive impairment (CI) between $\mathrm{Cl}$ and non- $\mathrm{Cl}$ groups.

\begin{tabular}{lccrr}
\hline Variables & Cl group (16) & Non-Cl group (98) & $\boldsymbol{t} / \boldsymbol{\chi}^{2} / \boldsymbol{Z}$ & $\boldsymbol{P}$ value \\
\hline Age (years) & $73.63 \pm 8.43$ & $68.56 \pm 5.97$ & 2.958 & 0.004 \\
Male & $10(62.5)$ & $50(51.0)$ & 0.727 & 0.394 \\
Education (years) & $10.00 \pm 1.37$ & $11.96 \pm 2.00$ & 4.016 & $<0.001$ \\
Living alone & $2(12.5)$ & $10(10.2)$ & 0.077 & 0.781 \\
Smoking & $2(12.5)$ & $14(14.3)$ & 0.036 & 0.849 \\
Diabetes & $4(25.0)$ & $15(15.3)$ & 0.931 & 0.335 \\
White matter lesion & & & & 1.580 \\
category & & & & \\
$\quad 0$ & $7(43.8)$ & $46(46.9)$ & 2.454 & 0.484 \\
1 & $4(25.0)$ & $34(34.7)$ & & \\
2 & $3(18.8)$ & $14(14.3)$ & & \\
3 & $2(5.3)$ & $4(4.1)$ & & \\
$\mathrm{OH}$ & $9(56.3)$ & $29(29.6)$ & 4.399 & 0.036 \\
\hline
\end{tabular}

TABLE 5 | Multifactor analysis for cognitive impairment.

\begin{tabular}{|c|c|c|c|c|c|c|c|}
\hline \multirow[t]{2}{*}{ Variables } & \multirow[t]{2}{*}{$B$} & \multirow[t]{2}{*}{ SE } & \multirow[t]{2}{*}{ Wald $\chi^{2}$} & \multirow[t]{2}{*}{$\boldsymbol{P}$} & \multirow[t]{2}{*}{ OR } & \multicolumn{2}{|c|}{$95 \% \mathrm{Cl}$ for OR } \\
\hline & & & & & & Lower & Upper \\
\hline $\begin{array}{l}\text { Orthostatic } \\
\text { hypotension }\end{array}$ & 1.398 & 0.645 & 4.704 & 0.030 & 4.047 & 1.144 & 14.313 \\
\hline Age & 0.181 & 0.057 & 10.177 & 0.001 & 1.199 & 1.072 & 1.340 \\
\hline $\begin{array}{l}\text { Education } \\
\text { (years) }\end{array}$ & -0.566 & 0.217 & 6.798 & 0.009 & 0.568 & 0.371 & 0.869 \\
\hline
\end{tabular}

not been studied in longitudinal studies. This study aimed to study this relationship by comparing $44 \mathrm{OH}$ patients with 88 healthy subjects after 4 years follow-up. Among the patients who were followed up, $23.7 \%$ of $\mathrm{OH}$ patients developed $\mathrm{CI}$, whereas only $9.2 \%$ of non-OH subjects developed this illness. The difference was significant. Furthermore, $\mathrm{OH}$ still remains an independent risk factor for CI even after excluding the influence of age and education years, indicating that increased blood pressure variance is related to the development of CI in the elderly. In this study, the subjects who were not followed up had lower education level, which was demonstrated to be a risk factor for CI in another study (6). Our findings are consistent with their results.

Results of this study are consistent with that of previous cross-sectional studies (16-19). However, cross-sectional studies can only provide a clue to the etiology of a disease, whereas longitudinal studies can reveal causation.
Elmstáhl and Rosén (20) reported their results about $\mathrm{OH}$ and $\mathrm{CI}$ in a longitudinal study. They monitored the EEG change among healthy females, which reflected the causal relationship between $\mathrm{OH}$ and $\mathrm{CI}$ (20). To our knowledge, this is the first study to investigate the relationship between $\mathrm{OH}$ and CI. Not all subjects in the study by Elmstáhl and Rosén fit the diagnostic criteria of $\mathrm{OH}$, which may have impacted their findings. This study found that age is an independent risk factor for CI. As age increases, the likelihood of developing CI also increases, which is consistent with the previous findings. Multiple mechanisms might explain the relationship between $\mathrm{CI}$ and $\mathrm{OH}$. Brain areas that are responsible for CI might regulate cardiovascular activities. Hence, neurodegeneration of these brain areas may be the cause of $\mathrm{CI}$ and $\mathrm{OH}(21)$. Studies have reported that $\mathrm{OH}$ leads to hypoperfusion of the frontal lobe, which could result in compromised executive functions of patients (22-25). Finally, similar to the relationship between hypotension and CI, long-term brain hypoperfusion caused by the large variance of blood pressure in $\mathrm{OH}$ patients leads to ischemic demyelinating WMLs, which accounts for the impaired cognition $(26,27)$.

This study used MMSE to assess the cognitive performance of all subjects. The reason for this is that MMSE is widely used in the field of dementia research and other batteries which are popular in the western world have not been validated for Chinese people due to culture difference. MMSE has a high sensitivity and specificity and has been widely used in clinical trials, and we believe that it can be a good tool for cognitive assessment.

There are some limitations in this study. First, the sample size is small due to our strict exclusion criteria, which might lead to the underestimated relationship between WML and CI. Second, development of $\mathrm{OH}$ in the control group was not considered during the follow-up period. So we suggest that future studies should increase the sample size and also use $\mathrm{OH}$ exposure time instead of $\mathrm{OH}$ exposure population to confirm the conclusion of this study. Third, this study used the MMSE score of 24 as the cutoff point for CI. A small number of our patients had a score between 24 and 27, which indicates that they had MCI when they were recruited. It is known that $\mathrm{MCI}$ has an annual conversion rate of $10.24 \%$ for dementia (28). Therefore, future large-scale studies can stratify their research design to include both MCI with $\mathrm{OH}$ and pure $\mathrm{OH}$ patients to clarify the relationship between $\mathrm{OH}$ and $\mathrm{CI}$.

\section{ETHICS STATEMENT}

This study was carried out in accordance with the recommendations of "Chinese guidelines in human research, The Human Research Ethics Committee of North Sichuan Branch, Shanghai No.1 People's Hospital, Shanghai Jiaotong University," with written informed consent from all subjects. All subjects gave written informed consent in accordance with the Declaration of Helsinki. The protocol was approved by the "The Human Research Ethics Committee of North Sichuan Branch, Shanghai No.1 People's Hospital, Shanghai Jiaotong University." 


\section{AUTHOR CONTRIBUTIONS}

SW, HL, and HH initiated this study. HH, TZ, ZW, and FL collected the clinical data and did statistical analysis. HL wrote this manuscript.

\section{REFERENCES}

1. Mayeux R, Reitz C, Brickman AM, Haan MN, Manly JJ, Glymour MM, et al. Operationalizing diagnostic criteria for Alzheimer's disease and other agerelated cognitive impairment - part 1. Alzheimers Dement (2011) 7(1):15-34. doi:10.1016/j.jalz.2010.11.005

2. Litvan I, Goldman JG, Tröster AI, Schmand BA, Weintraub D, Petersen RC, et al. Diagonstic criteria for mild cognitive impairment in Parkinson's disease: Movement Disorder Society Task Force guidelines. Mov Disord (2012) 27(3):349-56. doi:10.1002/mds. 24893

3. Brodziak A, Wolińska A, Kolat E, Różyk-myrta A. Guidelines for prevention and treatment of cognitive impairment in the elderly. Med Sci Monit (2015) 21:585-97. doi:10.12659/MSM.892542

4. Kilander L, Nyman H, Boberg M, Hansson L, Lithell H. Hypertension is related to cognitive impairment: a 20-year follow-up of 999 men. Hypertension (1998) 31(3):780-6. doi:10.1161/01.HYP.31.3.780

5. Reitz C, Tang MX, Manly J, Mayeux R, Luchsinger JA. Hypertension and the risk of mild cognitive impairment. Arch Neurol (2007) 64(12):1734-40. doi:10.1001/archneur.64.12.1734

6. Huang H, Feng Z, Liu F. Effect of hypotension on cognitive function in elderly people. Chin J Geritr Heart Brain Vessel Dis (2013) 15(2):164-7. doi:10.3969/j. issn.1009-0126.2013.02.016

7. Mossello E, Pieraccioli M, Nesti N, Bulgaresi M, Lorenzi C, Caleri V, et al. Effects of low blood pressure in cognitively impaired elderly patients treated with antihypertensive drugs. JAMA Intern Med (2015) 175(4):578-85. doi:10.1001/jamainternmed.2014.8164

8. Sambati L, Calandra-Buonaura G, Poda R, Guaraldi P, Cortelli P. Orthostatic hypotension and cognitive impairment: a dangerous association? Neurol Sci (2014) 35(6):951-7. doi:10.1007/s10072-014-1686-8

9. Colloby SJ, Vasudev A, O’Brien JT, Firbank MJ, Parry SW, Thomas AJ. Relationship of orthostatic blood pressure to white matter hyperintensities and subcortical volumes in late-life depression. Br J Psychiatry (2011) 199(5):404-10. doi:10.1192/bjp.bp.110.090423

10. Eigenbrod ML, Rose KM, Couper DJ, Arnett DK, Smith R, Jones D. Orthostatic hypotension as a risk factor for stroke: the atherosclerosis risk in communities (ARIc) study, 1987-1996. Stroke (2000) 31(10):2307-13. doi:10.1161/01. STR.31.10.2307

11. Dubois B, Feldman HH, Jacova C, Dekosky ST, Barberger-Gateau P, Cummings J, et al. Research criteria for the diagnosis of Alzheimer's disease: revising the NINCDS-ADRDA criteria. Lancet Neurol (2007) 6(8):734-46. doi:10.1016/ S1474-4422(07)70178-3

12. Fazekas F, Chawluk JB, Alavi A, Hurtig HI, Zimmerman RA. MR signal abnormalities at $1.5 \mathrm{~T}$ in Alzheimer's dementia and normal aging. AJR Am J Roentgenol (1987) 149(2):351-6. doi:10.2214/ajr.149.2.351

13. Jia J, Wang Y, Li Y, Chen X, Ding X, Zhang Z, et al. Guidelines for diagnosis and treatment of dementia and cognitive impairment in China (II). Natl Med J China (2011) 91(10):651-5. doi:10.3760/cma.j.issn.0376-2491.2011.10.002

14. Gangavati A, Hajjar I, Quach L, Jones RN, Kiely DK, Gagnon P, et al. Hypertension, orthostatic hypotension, and the risk of falls in a communitydwelling elderly population: the maintenance of balance, independent living, intellect, and zest in the elderly of Boston study. J Am Geriatr Soc (2011) 59(3):383-9. doi:10.1111/j.1532-5415.2011.03317.x

15. Rockwood M, Howlett SE, Rockwood K. Orthostatic hypotension (OH) and mortality in relation to age, blood pressure and frailty. Arch Gerontol Geriatr (2012) 54(3):e255-60. doi:10.1016/j.archger.2011.12.009

\section{ACKNOWLEDGMENTS}

We thank Shanghai Hongkou District Municipal Commission of Health and Family Planning for its grant support for the Early Identification of Cognitive Impairment in Shanghai, China (1203-01).

16. Czajkowska J, Ozhog S, Smith E, Perlmuter LC. Cognition and hopelessness in association with subsyndromal orthostatic hypotension. J Gerontol A Biol Sci Med Sci (2010) 65(8):873-9. doi:10.1192/bjp.bp.110.090423

17. Mehrabian S, Duron E, Labouree F, Rollot F, Bune A, Traykov L, et al. Relationship between orthostatic hypotension and cognitive impairment in the elderly. JNeurol Sci (2010) 299(1-2):45-8. doi:10.1016/j.jns.2010. 08.056

18. FuruängL, Siennicki-Lantz A, ElmståhlS. Reduced cerebral perfusion in elderly men with silent myocardial ischaemia and nocturnal blood pressure dipping. Atherosclerosis (2011) 214(1):231-6. doi:10.1016/j.atherosclerosis.2010. 10.043

19. Perlmuter LC, Sarda G, Casavant V, O'Hara K, Hindes M, Knott PT, et al. A review of orthostatic blood pressure regulation and its association with mood and cognition. Clin Auton Res (2012) 22(2):99-107. doi:10.1007/ s10286-011-0145-3

20. Elmstáhl S, Rosén I. Postural hypotension and EEG variables predict cognitive decline: results from a 5-year follow-up of healthy elderly women. Dement Geriatr Cogn Disord (1997) 8(3):180-7. doi:10.1159/000106629

21. Idiaquez J, Roman GC. Autonomic dysfunction in neurodegenerative dementias. J Neurol Sci (2011) 305(1):22-7. doi:10.1016/j.jns.2011.02.033

22. Gibbons $\mathrm{CH}$, Centi J, Vernino S, Freeman R. Autoimmune autonomic ganglionopathy with reversible cognitive impairment. Arch Neurol (2012) 69(4):461-6. doi:10.1001/archneurol.2011.2372

23. Kim JS, Oh YS, Lee KS, Kim YI, Yang DW, Goldstein DS. Association of cognitive dysfunction with neurocirculatory abnormalities in early Parkinson disease. Neurology (2012) 79(13):1323-31. doi:10.1212/WNL. 0b013e31826clacd

24. Poda R, Guaraldi P, Solieri L, Calandra-Buonaura G, Marano G, Gallassi $\mathrm{R}$, et al. Standing worsens cognitive functions in patients with neurogenic orthostatic hypotension. Neurol Sci (2012) 33(2):469-73. doi:10.1007/ s10072-011-0746-6

25. Pilleri M, Facchini S, Gasparoli E, Biundo R, Bernardi L, Marchetti M, et al. Cognitive and MRI correlates of orthostatic hypotension in Parkinson's disease. J Neurol (2013) 260(1):253-9. doi:10.1007/s00415-012-6627-y

26. Duschek S, Schandry R. Deficient adjustment of cerebral blood flow to cognitive activity due to chronically low blood pressure. Biol Psychol (2006) 72:311-7. doi:10.1016/j.biopsycho.2005.12.003

27. Stegagno L, Patritti D, Duschek S, Herbert B, Schandry R. Cerebral blood flow in essential hypotension during emotional activation. Psychophysiology (2007) 44(2):226-32. doi:10.1111/j.1469-8986.2007.00507.x

28. Bruscoli M, Lovestone S. Is MCI really just early dementia? A systematic review of conversion studies. Int Psychogeriatr (2004) 16:129-40. doi:10.1017/ S1041610204000092

Conflict of Interest Statement: The authors declare that the research was conducted in the absence of any commercial or financial relationships that could be construed as a potential conflict of interest.

Copyright (C) 2017 Huang, Zheng, Liu, Wu, Liang and Wang. This is an open-access article distributed under the terms of the Creative Commons Attribution License (CC $B Y)$. The use, distribution or reproduction in other forums is permitted, provided the original author(s) or licensor are credited and that the original publication in this journal is cited, in accordance with accepted academic practice. No use, distribution or reproduction is permitted which does not comply with these terms. 